\title{
The urea cycle of Helicobacter pylori
}

\author{
George L. Mendz $z^{1}$ and Stuart L. Hazell ${ }^{2}$ \\ Author for correspondence: George L. Mendz. Tel: +612385 2042. Fax: +61231362712. \\ e-mail: G.Mendz@unsw.EDU.AU
}

Schools of Biochemistry and Molecular Genetics' and Microbiology and Immunology2, The University of New South Wales, Sydney, NSW 2052, Australia

\begin{abstract}
The presence and activities of the enzymes of the urea cycle in the bacterium Helicobacter pylori were investigated employing one- and two-dimensional NMR spectroscopy and radioactive tracer analysis. Cell suspensions, lysates and membrane preparations generated L-ornithine and ammonium at high rates in incubations with L-arginine, indicating the presence of arginase activity. Anabolic ornithine transcarbamoylase (OrCase) activity was identified by the formation of heat-stable products in incubations of cell-free extracts with ornithine and radiolabelled carbamoyl phosphate. The heat-labile product that resulted from incubations of cell-free extracts with citrulline radiolabelled in the guanidino moiety revealed the presence of catabolic OTCase activity. Argininosuccinate formation and catalysis indicated the presence of argininosuccinate synthetase and argininosuccinase activities. The findings suggested that $\boldsymbol{H}$. pylori has a urea cycle which acts as an effective mechanism to extrude excess nitrogen from cells.
\end{abstract}

Keywords: urea cycle, NMR spectroscopy, Helicobacter pylori, arginase

\section{INTRODUCTION}

Helicobacter comprises a genus of Gram-negative, microaerophilic, vibrioid bacteria with a unique habitat in the stomach and upper intestine of animals. Several species are found as part of the normal microbiota in animals; for example, $H$. felis in cats and dogs, $H$. acinonyx in cheetahs, $H$. mustelae in ferrets, $H$. muridarum in mice and $H$. pullorum in chickens (Lee, 1989; Eaton et al., 1993; Stanley et al., 1994). In humans, $H$. beilmanii and $H$. pylori colonize the upper gastrointestinal tract (Lee, 1989; O'Rourke et al., 1992). H. pylori has been established as the major aetiological agent of active chronic gastritis (Goodwin et al., 1986; Morris \& Nicholson, 1987) and peptic ulcers (Graham, 1991; Calam, 1993), and has recently been declared a group 1 gastric cancer carcinogen (Vanzanten \& Sherman, 1994; International Agency for Cancer Research, 1994).

Bacteria require large quantities of nitrogen, since this bioelement amounts to about $10 \%$ of their dry weight (Gottschalk, 1985). In micro-organisms, nitrogen occurs naturally in the form of ammonia, nitrate, nitrite, nitrogen-containing organic compounds and molecular nitrogen. The human pathogen $H$. pylori is capable of growing and proliferating in a broth containing only

Abbreviations: DQF-COSY, double quantum-filtered ${ }^{1} \mathrm{H}$ homonuclear correlated; OTCase, ornithine transcarbamoylase. amino acids as basic nutrients, and does not require saccharides for growth under culturing conditions in which amino acids are in sufficient supply (Nedenskov, 1994; Reynolds \& Penn, 1994; Mendz \& Hazell, 1995). Several amino acids are transformed into metabolites of the central intermediary metabolism via deamination reactions proceeding at fast rates, with concomitant production of considerable quantities of free ammonium (Mendz \& Hazell, 1993, 1995; Mendz et al., 1994). These findings suggested that in the physiology of the microorganism there would be effective mechanisms to manage the significant amounts of ammonium formed.

The aim of this work was to investigate the metabolic networks employed by the bacterial cells to excrete excess nitrogen and maintain cell nitrogen balance. The presence and activities of the enzymes of the urea cycle were investigated employing NMR spectroscopy, radioactive tracer analysis and growth culture techniques.

\section{METHODS}

Materials. Blood Agar Base no. 2, Columbia Agar Base, Isosensitest broth and horse serum were from Oxoid. LArginine, argininosuccinate, L-aspartate, carbamoyl phosphate, BSA fraction V, bovine liver catalase, L-citrulline, L-ornithine, $N \alpha$-acetylornithine, $N \alpha$-carbamoylornithine, ornithine transcarbamoylase (OTCase), polymyxin B and trimethoprim were from Sigma; amphotericin B (Fungizone) was from Squibb; vancomycin was from Eli Lilly; and ATP was from Boehringer. 
Sterile $0 \cdot 2 \mu \mathrm{m}$ Minisart filters were from Sartorius, and selfvented tissue culture flasks and sterile microtitre trays were from Corning. $\quad\left[{ }^{14} \mathrm{C}\right]$ Carbamoyl phosphate $\left[13.9 \mathrm{mCi} \mathrm{mmol}^{-1}\right.$ $\left.\left(514.3 \mathrm{MBq} \mathrm{mmol}^{-1}\right)\right]$ and $\mathrm{L}-\left[\right.$ ureido $\left.^{-14} \mathrm{C}\right]$ citrulline $[55 \mathrm{mCi}$ $\left.\mathrm{mmol}^{-1}\left(2.03 \mathrm{GBq} \mathrm{mmol}{ }^{-1}\right)\right]$ were from New England Nuclear (DuPont). All other reagents were of analytical grade.

Bacterial cultures and preparation. $H$. pylori laboratoryadapted strains NCTC 11639, N6, N6ure G::Km, UNSW P10 and UNSW RU1, and low-passage wild-type strains UNSW 920023, UNSW 920042, UNSW 920106 and UNSW 10593/5 were grown on Blood Agar Base no. 2 plates supplemented with $5 \%(\mathrm{v} / \mathrm{v})$ horse blood, polymyxin $\mathrm{B}\left(1 \cdot 25 \mathrm{U}^{-1}\right)$, trimethoprim $\left(5 \mathrm{mg}^{-1}\right)$, vancomycin $\left(10 \mathrm{mg}^{-1}\right)$ and amphotericin $\mathrm{B}(2 \cdot 5 \mathrm{mg}$ $\left.\mathrm{I}^{-1}\right)$. The low-passage strains were passaged less than ten times. Strain N6ure $G:: \mathrm{Km}$ is a urease-negative strain derived from strain N6 by insertional mutagenesis in the ure $G$ gene, which results in failure to activate the urease apoenzyme (Ferrero $e t$ al., 1992). Cultures were passaged every $32-38 \mathrm{~h}$ and incubated in a Forma Stericult incubator in an atmosphere of $10 \% \mathrm{CO}_{2}$ in air, $95 \%$ humidity at $37{ }^{\circ} \mathrm{C}$. Cells were harvested in exponential phase (approx. $24 \mathrm{~h}$ ) in sterile $\mathrm{NaCl}(0 \cdot 9 \%, \mathrm{w} / \mathrm{v})$, checked for purity using phase-contrast microscopy, and tested for urease and catalase activity. Cells were washed three times by centrifuging at $17000 \mathrm{~g}\left(6^{\circ} \mathrm{C}, 3 \mathrm{~min}\right)$, discarding the supernatant, collecting the pellet and resuspending it in saline. After the final wash, packed cells were resuspended in saline and employed as inoculum for different experiments.

Cells were grown in liquid cultures of Isosensitest broth supplemented with BSA $(0.5 \%, \mathrm{w} / \mathrm{v})$ and catalase $(0 \cdot 1 \%, \mathrm{w} / \mathrm{v})$ unless otherwise specified, and incubated in a Forma Stericult incubator in an atmosphere of $10 \% \mathrm{CO}_{2}$ in air, $95 \%$ humidity at $37^{\circ} \mathrm{C}$. Bacterial growth was monitored by the changes in the $\mathrm{OD}_{600}$ of cell suspensions, and bacterial viability was measured by the number of colonies formed using the method of Miles \& Misra (1938). At regular intervals, samples were taken from the cultures, their optical density was measured and the cultures were inoculated onto Blood Agar Base no. 2 plates at dilutions between $10^{\circ}$ and $10^{-6}$.

Bacterial lysates wete prepared by harvesting cells in sterile $\mathrm{KCl}$ $(150 \mathrm{mM})$ and centrifuging them at $17000 \mathrm{~g}\left(6^{\circ} \mathrm{C}, 8 \mathrm{~min}\right)$; the supernatant was discarded and the pellet was collected and resuspended in $\mathrm{KCl}$. The procedure was repeated three times. Following the final wash, packed cells were resuspended to a concentration of approximately $10^{8}-10^{9} \mathrm{cells} \mathrm{ml}^{-1}$ in sterile $\mathrm{KCl}$. Lysates were prepared by twice freezing in liquid nitrogen and thawing packed-cell suspensions; phase-contrast microscopy indicated that more than $99 \%$ of the cells were lysed. Lysates were separated into pellet and supernatant fractions by centrifugation at $17000 \mathrm{~g}\left(6^{\circ} \mathrm{C}, 8 \mathrm{~min}\right)$.

Arginine utilization and identification of catabolic products. Following the final wash after harvesting, packed cells were resuspended to a concentration of approximately $10^{8}-10^{9}$ cells $\mathrm{ml}^{-1}$ in Isosensitest broth supplemented with BSA $(0.5 \%, \mathrm{w} / \mathrm{v})$ and catalase $(0 \cdot 1 \%, \mathrm{w} / \mathrm{v})$ or in $\mathrm{NaCl}(150 \mathrm{mM})$. For NMR measurements, cell suspensions were transferred to 5 or $10 \mathrm{~mm}$ tubes (Wilmad) which, after addition of L-arginine, were plugged with cotton wool and incubated in air for up to $24 \mathrm{~h}$. Incubation products were separated by centrifuging samples at $17000 \mathrm{~g}\left(6^{\circ} \mathrm{C}, 8 \mathrm{~min}\right)$, collecting the supernatants, and filtering through membranes with an $M_{\mathrm{r}}$ cut-off of 1000 .

NMR spectroscopy. Two-dimensional NMR ${ }^{13} \mathrm{C}-{ }^{1} \mathrm{H}$ heteronuclear-shift-correlated spectra were acquired in a Bruker AM500 spectrometer using a standard program. The acquisition parameters were: ${ }^{1} \mathrm{H}$ spectral width $4504.5 \mathrm{~Hz},{ }^{13} \mathrm{C}$ spectral width $20833.33 \mathrm{~Hz}$, recycling time $2 \cdot 0 \mathrm{~s}$, and 240 free-induction decays were averaged over 4096 memory locations. Contour maps of $4096 \times 1024$ data points were obtained from 256 individual experiments by zero filling in the evolution time domain before Fourier transformation. The plots are in absolute-value mode, with Gaussian apodization with a linebroadening of $2 \mathrm{~Hz}$ along the acquisition time domain, and sinebell apodization with a shift for sine-bell window of $\pi / 10$ along the evolution time domain. ${ }^{13} \mathrm{C}$ chemical shifts are given relative to $\mathrm{L}-\mathrm{Arg}-\alpha-\mathrm{CH}$ at $55 \cdot 32$ p.p.m.

Two-dimensional double quantum-filtered ${ }^{1} \mathrm{H}$ homonuclear correlated (DQF-COSY) spectra with presaturation of the solvent resonance for $1 \mathrm{~s}$ were acquired employing a standard program in a Bruker AM-500 spectrometer. The acquisition parameters were: spectral width $2000 \mathrm{~Hz}, 0.512 \mathrm{~s}$ acquisition time, $1.512 \mathrm{~s}$ recycling time, and 32 free-induction decays were averaged over 2048 memory locations. Contour maps of $2048 \times$ 1024 data points were obtained from 1024 individual experiments. The plots are in absolute-value mode, with square sinebell apodization and a shift for sine-bell window of $\pi / 2$ along the acquisition and the evolution time domains. ${ }^{1} \mathrm{H}$ chemical shifts are given relative to sodium 3-(trimethylsilyl)-1-propanesulfonate at 0 p.p.m.

For studies of metabolism employing ${ }^{1} \mathrm{H}-\mathrm{NMR}$ spectroscopy, H. pylori was prepared in suspensions of packed cells in $\mathrm{NaCl}$ $(150 \mathrm{mM})$ or lysates in $\mathrm{KCl}(150 \mathrm{mM})$, placed in $5 \mathrm{~mm}$ tubes (Wilmad), and the substrates were added to start the reactions. Free-induction decays were collected using a Bruker AM-500 spectrometer, operating in the pulsed Fourier transform mode with quadrature detection. Measurements were carried out at $37{ }^{\circ} \mathrm{C} .{ }^{1} \mathrm{H}$ spectra were acquired with presaturation of the water resonance. The instrumental parameters were: spectral width $5434.78 \mathrm{~Hz}$, memory size $8 \mathrm{~K}$, acquisition time $0.754 \mathrm{~s}$, number of transients 144-256 and relaxation delays with solvent presaturation $1 \cdot 26-2 \cdot 75 \mathrm{~s}$. Exponential filtering of $1 \mathrm{~Hz}$ was applied prior to Fourier transformation. Chemical shifts are quoted relative to sodium 3-(trimethylsilyl)-1-propanesulfonate at 0 p.p.m.

One-dimensional natural abundance ${ }^{13} \mathrm{C}$-NMR spectra were acquired with composite pulse decoupling. The instrumental parameters for the AM-500 spectrometer were: operating frequency $125.77 \mathrm{MHz}$, spectral width $29411.76 \mathrm{~Hz}$, memory size $16 \mathrm{~K}$, acquisition time $4.279 \mathrm{~s}$, pulse angle $65^{\circ}(4 \mu \mathrm{s})$ and the number of transients 2000 . Exponential filtering of $3 \mathrm{~Hz}$ was applied prior to Fourier transformation. The instrumental parameters for the ACP-300 spectrometer were: operating frequency $75.5 \mathrm{MHz}$, spectral width $16129 \mathrm{~Hz}$, memory size $16 \mathrm{~K}$, acquisition times $1.508 \mathrm{~s}$, number of transients 3000 and pulse angle $66^{\circ}(9 \mu \mathrm{s})$. Exponential filtering of $2 \mathrm{~Hz}$ was applied prior to Fourier transformation.

One-dimensional ${ }^{14} \mathrm{~N}-\mathrm{NMR}$ spectra were acquired with composite pulse decoupling. The instrumental parameters for the ACP-300 spectrometer were: operating frequency $21.69 \mathrm{MHz}$, spectral width $13157.89 \mathrm{~Hz}$, memory size $16 \mathrm{~K}$, relaxation delay $0.626 \mathrm{~s}$ and the number of transients 2944 . Spectra were acquired with a standard Bruker antiringing program. Exponential filtering of $40 \mathrm{~Hz}$ and a left shift of two data points were applied prior to Fourier transformation.

The time-evolution of substrates and products was followed by acquiring sequential spectra of the reactions. Progress curves were obtained by measuring the integrals of substrate and product resonances at each point in time. Maximal rates were calculated from good fits (correlation coefficients $\geqslant 0.99$ ) of the data to straight lines for $30-60 \mathrm{~min}$ of the incubations. 
Calibrations of the peaks arising from substrates were performed by extrapolating the resonance intensity data to zero time and assigning the appropriate concentration value to this intensity. The intensity of resonances corresponding to products were calibrated by adding the appropriate metabolite to cell suspensions and constructing standard concentration curves.

Radioactive tracer analysis. The activity of anabolic OTCase (EC 2.1.3.3) was measured by the incorporation of the radiolabel of $\left[{ }^{14} \mathrm{C}\right]$ carbamoyl phosphate into citrulline, a heatstable product, according to the following reaction

$$
\begin{aligned}
\mathrm{H}_{2} \mathrm{~N}^{14} \mathrm{CO}_{2} \mathrm{P}+\mathrm{H}_{2} \mathrm{~N}\left(\mathrm{CH}_{2}\right)_{3} \mathrm{CH}\left(\mathrm{NH}_{2}\right) \mathrm{CO}_{2}^{-} & \rightarrow \mathrm{H}_{2} \mathrm{~N}^{14} \mathrm{CONH}\left(\mathrm{CH}_{2}\right)_{3} \mathrm{CH}\left(\mathrm{NH}_{2}\right) \mathrm{CO}_{2}^{-}
\end{aligned}
$$

Reaction mixtures contained $200 \mathrm{mM} \mathrm{HEPES} / \mathrm{KOH}, \mathrm{pH} 7$, $40 \mathrm{mM}$ ornithine, $0.4 \mathrm{mM}$ carbamoyl phosphate $[0 \cdot 1 \mu \mathrm{Ci}$ $\left.\mu \mathrm{mol}^{-1}\left(3.7 \mathrm{kBq} \mu \mathrm{mol}^{-1}\right)\right]$ and $20-50 \mu \mathrm{l}$ supernatants in a total volume of $200 \mu \mathrm{l}$. In control experiments, bacterial supernatants were substituted by $\mathrm{KCl}$. Incubations were carried out at $37^{\circ} \mathrm{C}$ in a stirred water-bath. The reactions were terminated by the addition of $100 \mu \mathrm{l} 3 \mathrm{M}$ formic acid and heated at $80^{\circ} \mathrm{C}$ for $6 \mathrm{~min}$ to decompose any unused carbamoyl phosphate. A small amount of dry ice was added and the mixtures were allowed to stand for $20 \mathrm{~min}$ in a fume hood. The samples were freeze-dried and redissolved in $200 \mu \mathrm{l}$ water. Duplicate $100 \mu \mathrm{l}$ samples were placed in scintillation vials, $10 \mathrm{ml}$ toluene/Triton X-100 (2:1, $\mathrm{v} / \mathrm{v}$ ) scintillant solution was added, and the radioactivity was measured in a Packard Tri-Carb 1900TR Liquid Scintillation Analyzer. Enzyme activity was measured in preparations with protein concentrations from 0.6 to $6.6 \mathrm{mg} \mathrm{m}^{-1}$. The formation of product was measured at $0,1,2,3,5,7,10,15,30$ and $40 \mathrm{~min}$. Under these conditions, the formation of product was linear. The kinetic parameters of OTCase were measured at an Lornithine concentration of $40 \mathrm{mM}$ and a carbamoyl phosphate concentration range of 0.025 to $0.6 \mathrm{mM}$, at $37^{\circ} \mathrm{C}$ and at fixed time-points of $5,8,10,15$ or $40 \mathrm{~min}$. The kinetic constants $K_{\mathrm{m}}$ and $V_{\max }$ were calculated by non-linear regression analysis employing the program Enzyme Kinetics (Trinity Software, Campton, NH, USA).

Catabolic OTCase activities were measured by the loss of the radiolabel of $\mathrm{L}-\left[\right.$ ureido $\left.{ }^{14} \mathrm{C}\right]$ citrulline as it was converted to carbamoyl phosphate and L-ornithine in the reverse reaction of the above equation. Reaction mixtures contained $200 \mathrm{mM}$ HEPES/KOH, pH 7, $10 \mathrm{mM}$ L-citrulline $\left[0 \cdot 1 \mu \mathrm{Ci} \mu \mathrm{mol}^{-1}\right.$ $\left.\left(3.7 \mathrm{kBq} \mu \mathrm{mol}^{-1}\right)\right], 20 \mathrm{mM}$ inorganic phosphate and $20 \mu \mathrm{l}$ supernatants in a total volume of $200 \mu \mathrm{l}$. In control experiments, bacterial supernatants were substituted by $\mathrm{KCl}$. The experimental protocol was the same as for measuring anabolic OTCase activity, but in this case the residual radioactivity measured corresponded to the L-citrulline substrate that was not metabolized.

\section{RESULTS}

\section{Utilization of arginine by $\boldsymbol{H}$. pylori cells}

Rapid transformation of arginine was observed in suspensions of bacterial cells incubated in Isosensitest broth supplemented with this amino acid (Fig. 1). Similar observations were made for cells of all the strains suspended in $\mathrm{NaCl}(150 \mathrm{mM})$ with arginine added as the sole substrate, and for suspensions of bacterial lysates in $\mathrm{KCl}(150 \mathrm{mM})$. It was also possible to follow the metabolism of arginine by cell suspensions or lysates in time-courses acquired using ${ }^{1} \mathrm{H}$ - or ${ }^{14} \mathrm{~N}-\mathrm{NMR}$ spectro-

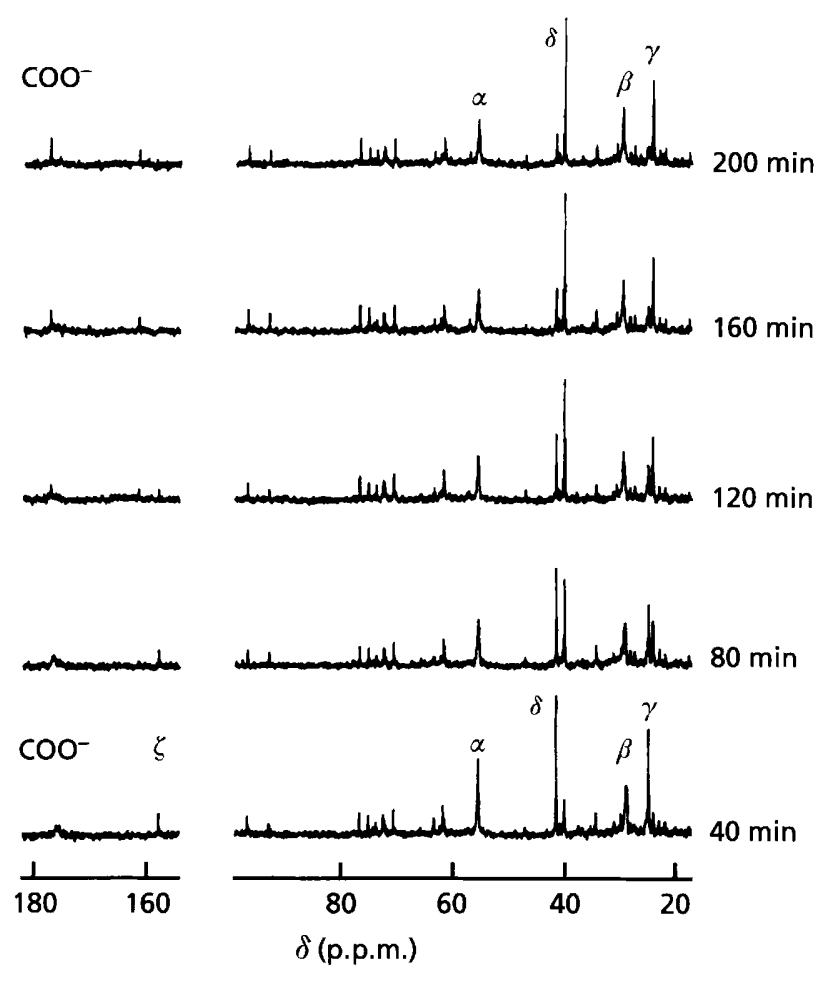

Fig. 1. ${ }^{13} \mathrm{C}$-NMR spectra of a time-course of the conversion of Larginine by $H$. pylori cells suspended in Isosensitest broth with BSA $(0.5 \%)$ and catalase $(0.1 \%)$. The substrate concentration was $40 \mathrm{mM}$. The resonances corresponding to the $\alpha, \beta, \gamma, \delta$ and $\zeta$ carbons of L-arginine are indicated on the bottom spectrum, and those corresponding to L-ornithine are indicated on the top spectrum. The time at which each spectrum was acquired is shown on the right-hand side.

scopy. The mean rate of arginine conversion to ornithine by lysates of strain UNSW 920023 in the presence of a saturating concentration $(60 \mathrm{mM})$ of substrate was $91.2 \pm 0.9 \mathrm{nmol} \mathrm{min}^{-1}$ (mg protein) $)^{-1}(n=6)$. The measured rates depended on the strain used, and the values differed up to one order of magnitude between strains. This catabolic activity was associated with the membrane fraction obtained by centrifugation of bacterial lysates; less than $5 \%$ of activity was measured in the supernatant fraction.

\section{Identification of metabolic products}

During incubations of L-arginine with lysates, the $\operatorname{six}{ }^{13} \mathrm{C}$ NMR resonances arising from its carboxylic, guanidino $\zeta$ and aliphatic $\alpha, \beta, \gamma$ and $\delta$ carbon atoms disappeared from the spectra of the suspensions and another five resonances at $174.97,55 \cdot 20,40 \cdot 01,28.40$ and 23.74 p.p.m. emerged. Two-dimensional NMR techniques were employed to identify the metabolites from which these new resonances arose. The ${ }^{13} \mathrm{C}-{ }^{1} \mathrm{H}$ heteronuclear-shift-correlated contour map of ultrafiltrates from incubation products showed correlations between the aliphatic carbon resonances at $55 \cdot 20,40 \cdot 01,28 \cdot 40$ and 23.74 p.p.m. and proton resonances at $4.389,3.178,1.900,1.823$ and 1.734 p.p.m., 


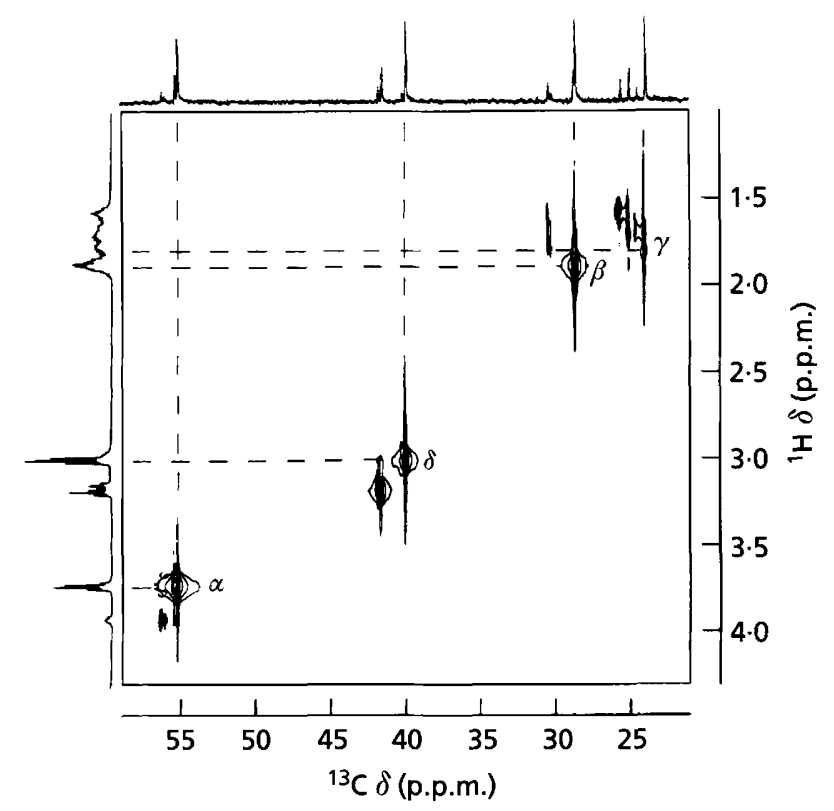

Fig. 2. Aliphatic region of the two-dimensional ${ }^{13} \mathrm{C}-{ }^{1} \mathrm{H}$ shiftcorrelated contour map of ultrafiltrates from incubations of $H$. pylori cells, suspended in $\mathrm{NaCl}$, with L-arginine. The resonances corresponding to the product L-ornithine are indicated on the figure. The natural abundance ${ }^{13} \mathrm{C}$ spectrum is shown at the top, and the ${ }^{1} \mathrm{H}$ spectrum is shown on the left-hand side. The correlations between the resonances in the ${ }^{13} \mathrm{C}$ and ${ }^{1} \mathrm{H}$ spectra are indicated by dashed lines.

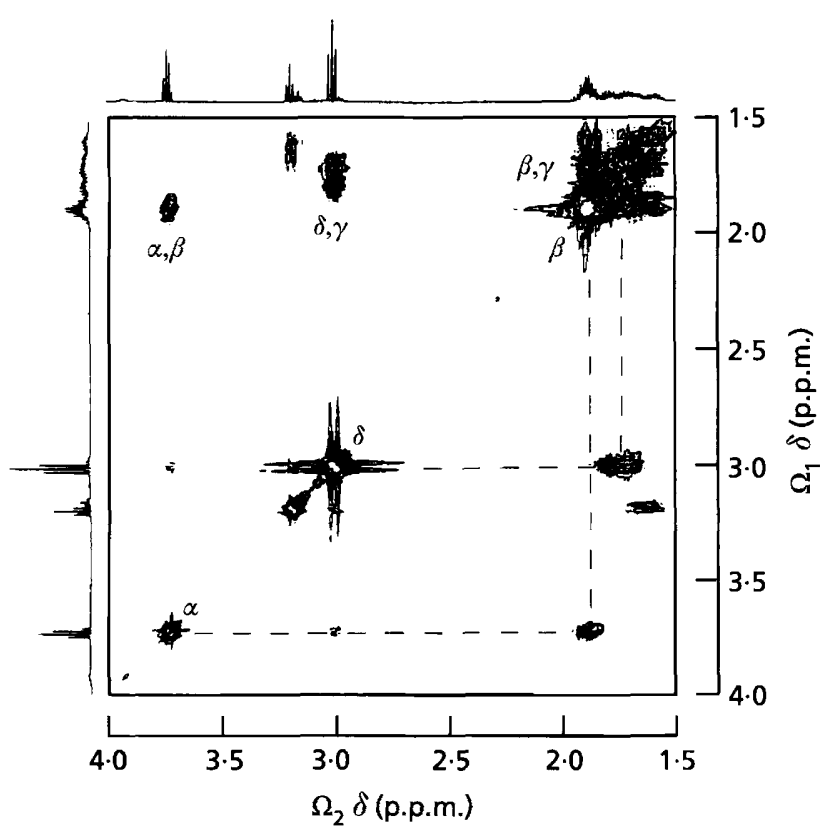

Fig. 3. Aliphatic region of the two-dimensional DQF-COSY contour map of ultrafiltrates from incubations of $\mathrm{H}$. pylori cells, suspended in $\mathrm{NaCl}$, with L-arginine. Indicated on the figure are the L-ornithine resonances corresponding to the $\alpha, \beta$ and $\delta$ protons, and the $\alpha, \beta, \beta, \gamma$ and $\delta, \gamma$ cross-peaks. Dashed lines show the connectivities between the different resonances of $L-$ ornithine. The one-dimensional ${ }^{1} \mathrm{H}$ spectrum is shown at the top and on the left-hand side.

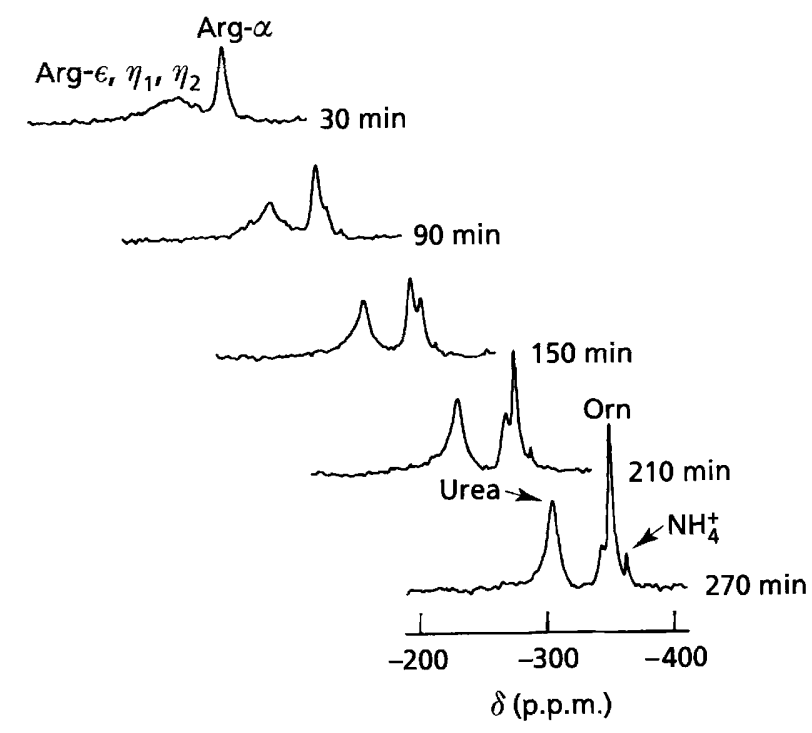

Fig. 4. ${ }^{14} \mathrm{~N}$ spectra of a time-course of mutant urease-negative H. pylori strain N6ure G:: Km cells in $\mathrm{NaCl}$ incubated with $50 \mathrm{mM}$ L-arginine as the sole substrate at $37^{\circ} \mathrm{C}$. The resonances corresponding to Arg- $\alpha,-\varepsilon,-\eta_{1}$ and $-\eta_{2}$, ornithine (Orn), urea and $\mathrm{NH}_{4}^{+}$are indicated on the figure. The time at which each spectrum was acquired is shown on the right-hand side.

respectively (Fig. 2). The DQF-COSY contour map of ultrafiltrates indicated connectivities between the following proton resonances: 4.389 and 1.900, 1.823 p.p.m.; 3.178 and 1.734 p.p.m.; and 1.734 and $1.900,1.823$ p.p.m. (Fig. 3). The correlations revealed by the heteronuclear correlation map together with the connectivities established by the homonuclear correlation plots, and the chemical shifts of all the resonances allowed a unique assignment of these peaks to the $\alpha\left({ }^{13} \mathrm{C}, 55 \cdot 20\right.$ p.p.m.; ${ }^{1} \mathrm{H}, \quad 4.389$ p.p.m. $), \quad \beta \quad\left({ }^{13} \mathrm{C}, 28.40\right.$ p.p.m. ; ${ }^{1} \mathrm{H}, 1.900$, 1.823 p.p.m. $), \gamma\left({ }^{13} \mathrm{C}, 23 \cdot 74\right.$ p.p.m. ; ${ }^{1} \mathrm{H}, 1.734$ p.p.m. $)$ and $\delta\left({ }^{13} \mathrm{C}, 40 \cdot 01\right.$ p.p.m. $;{ }^{1} \mathrm{H}, 3 \cdot 178$ p.p.m. $)$ atoms of ornithine. The peak at 174.97 p.p.m. corresponded to the carboxylic carbon of ornithine.

Time-courses of the metabolism of arginine as sole substrate in suspensions of cells in $\mathrm{NaCl}$ or lysates in $\mathrm{KCl}$ observed using ${ }^{14} \mathrm{~N}-\mathrm{NMR}$ spectroscopy showed the formation of $\mathrm{NH}_{4}^{+}$as well as ornithine. Incubations of cell suspensions of the urease-negative strain N6ure $G:: \mathrm{Km}$ with arginine as sole substrate yielded ornithine and urea as products (Fig. 4). These results indicated that Larginine is converted into ornithine and urea and that urea is hydrolysed to $\mathrm{NH}_{4}^{+}$and bicarbonate in suspensions of bacterial strains which express an active urease.

Arginine can be catabolized to ornithine via the arginase pathway in which arginine is converted directly to ornithine and urea, or via the arginine deiminase pathway in which arginine is converted to citrulline and ammonium, and citrulline reacting with inorganic phosphate yields ornithine and carbamoyl phosphate. To ascertain whether the catabolism of arginine in incubations where it was the only substrate proceeded via 


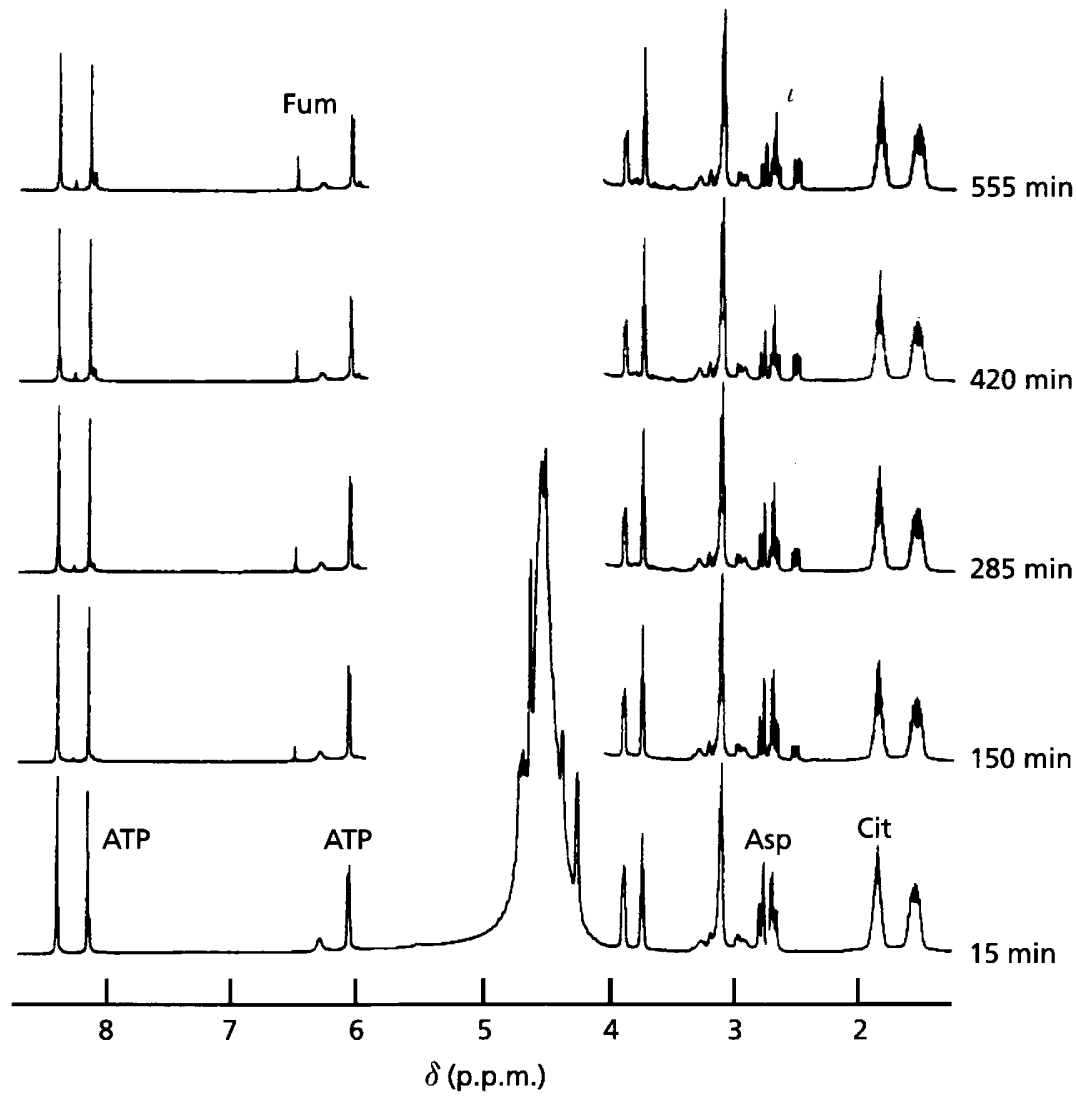

Fig. 5. ${ }^{1} \mathrm{H}$ spectra of a time-course of incubation of $H$. pylori cell-free extracts in $\mathrm{KCl}$ with $10 \mathrm{mM}$ L-aspartate, ATP and citrulline at $37^{\circ} \mathrm{C}$. The resonances corresponding to the substrates aspartate (Asp), ATP and citrulline (Cit) and the products fumarate (Fum) and argininosuccinate $l-\mathrm{CH}_{2}$ are indicated on the figure. The time at which each spectrum was acquired is shown on the right-hand side. The protein concentration of the cell-free extract was $3.35 \mathrm{mg} \mathrm{ml}^{-1}$.

citrulline, incubations were carried out with either citrulline as sole substrate or citrulline and ammonium as substrates. No utilization of citrulline by cells or lysates was observed under these conditions, indicating that the production of ornithine from arginine did not proceed via citrulline.

\section{OTCase activities}

Incubations of bacterial lysates from strain NCTC 11639 , UNSW P10 or UNSW 10593/5 with ornithine and $\left[{ }^{14} \mathrm{C}\right]$ carbamoyl phosphate showed the formation of heatresistant products. However, at $40 \mathrm{mM}$ ornithine and $\left[{ }^{14} \mathrm{C}\right]$ carbamoyl phosphate concentrations between $1 \mu \mathrm{M}$ and $15 \mathrm{mM}$, the amount of product formed in the presence of lysates was less than that formed under the same conditions using either $\mathrm{KCl}$ or heat-denatured lysates. When supernatants rather than lysates were employed, the amount of product formed was also less than that formed under the same conditions using either $\mathrm{KCl}$ or heatdenatured cell extracts. No significant activity was detected with the membrane fractions. In addition, poor results were obtained by fitting the data to MichaelisMenten kinetics, although the fits improved at low carbamoyl phosphate concentrations.

In order to understand these results, the chemical interactions of ornithine with carbamoyl phosphate were studied employing ${ }^{13} \mathrm{C}-\mathrm{NMR}$ spectroscopy. Time-courses showed that the substrates reacted to form $N \alpha$-carbamoylornithine and citrulline. $N \alpha$-Carbamoylornithine was also generated enzymically in the presence of bacterial lysates. The rates of chemical formation of $N \alpha$-carbamoylornithine and citrulline varied linearly with the concentration of the substrates, and at $50 \mathrm{mM}$ ornithine and $30 \mathrm{mM}$ carbamoyl phosphate were 19.9 and $9 \cdot 17 \mu \mathrm{M}$ $\min ^{-1}(n=3)$, respectively. The chemical reactions between ornithine and carbamoyl phosphate would explain the formation of heat-resistant products in the absence of bacterial extracts and the poor fits to Michaelis-Menten kinetics, but the formation of less product had to be attributed to the presence of enzymic reactions.

Employing ${ }^{13} \mathrm{C}-\mathrm{NMR}$ spectroscopy, it was found that $N \alpha$-acetylornithine reacted with carbamoyl phosphate to form $N \alpha$-acetylcitrulline in the presence or absence of cell extracts. With the aim of separating the contributions of the chemical and enzymic reactions to the formation of heat-resistant products, the interactions of $N \alpha$-acetylornithine with $\left[{ }^{14} \mathrm{C}\right]$ carbamoyl phosphate were investigated. In this case too, the amount of $N \alpha$-acetylcitrulline was paradoxically greater for the chemical reaction alone than under conditions in which the product was formed both chemically and enzymically. The results suggested the presence of an enzymic decomposition of $N \alpha$ acetylcitrulline by the cell extracts.

The catabolism of citrulline to ornithine and carbamoyl phosphate is catalysed by OTCases. The presence of 
catabolic OTCase activity was investigated by incubating $\left[\right.$ ureido- ${ }^{14} \mathrm{C}$ ]citrulline and inorganic phosphate with bacterial lysates. Under the experimental conditions, less than $5 \%$ citrulline was decomposed chemically, but the substrate was catabolized enzymically to ornithine and carbamoyl phosphate. Control experiments using [ureido${ }^{14} \mathrm{C}$ ]citrulline as sole substrate showed that no significant decomposition occurred in the presence of cells or lysates under the experimental conditions. For strain NCTC 11639 , initial rates of $733 \pm 100 \mu \mathrm{M} \min ^{-1}(n=2)$ were measured for an initial citrulline concentration of $10 \mathrm{mM}$. The reaction reached a steady state after $5 \mathrm{~min}$, and in this state $1.81 \pm 0.25 \mathrm{mM}$ of the initial citrulline had been converted to heat-labile $\left[{ }^{14} \mathrm{C}\right]$ carbamoyl phosphate and unlabelled ornithine. Under steady-state conditions, the rate of production of $\left[{ }^{14} \mathrm{C}\right]$ carbamoyl phosphate and ornithine must equal the rate of their conversion to the heat-stable compounds $\left[{ }^{14} \mathrm{C}\right]$ citrulline and $N \alpha-\left[{ }^{14} \mathrm{C}\right]$ carbamoylornithine. The chemical rates of production of the latter compounds at substrate concentrations of $1.81 \mathrm{mM}$ would be 0.021 and $0.043 \mu \mathrm{M} \mathrm{min} \mathrm{m}^{-1}$, respectively. The rates measured for enzymic citrulline catabolism together with the very small amounts of citrulline produced chemically could not account for the equilibrium observed at the steady state. The data suggested the presence of anabolic and catabolic OTCase activities in $H$. pylori cellfree extracts and explained the result that less product appeared to be formed chemically than both chemically and enzymically.

\section{Argininosuccinate synthesis and catabolism}

Employing ${ }^{1} \mathrm{H}$-NMR spectroscopy, the presence of argininosuccinate synthetase activity was observed in incubations of cell-free extracts of strain NCTC 11639 or UNSW 10593/5 with citrulline, ATP and L-aspartate (Fig. 5). Although there is considerable spectral overlap of resonances in the region of the spectrum between 2.5 and 3.5 p.p.m., the characteristic peaks arising from the $l$-methylene protons of argininosuccinate allowed the identification of this metabolite and measurement of catalytic rates. The resonances of the $\boldsymbol{l}$-methylene protons are characteristic of argininosuccinate, and have different spectral positions from the peaks arising from methylene protons of aspartate, asparagine or carbamoylaspartate, the other moieties with which they may be confused in these experiments. No argininosuccinate was generated in control experiments in which each one of the three substrates was left out. For the NCTC 11639 strain, the measured rate of argininosuccinate synthesis was $6.66 \pm 1.2 \mathrm{nmol} \mathrm{min}{ }^{-1}$ (mg protein $)^{-1}(n=3)$. No activity was detected in membrane fractions under the experimental conditions employed.

Argininosuccinase activity was identified in incubations of whole bacterial lysates of strain NCTC 11639, UNSW P10, UNSW RU1, N6, UNSW 90023 or UNSW 10593/5 with argininosuccinate as the sole substrate, employing ${ }^{1} \mathrm{H}-\mathrm{NMR}$ spectroscopy. Fumarate was generated at the beginning of the incubations and this intermediate was converted to succinate, acetate, lactate and alanine (Fig.
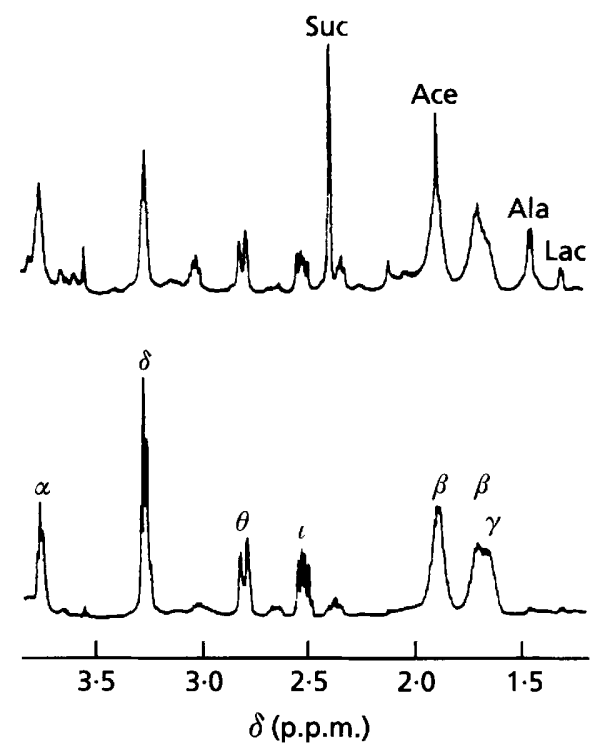

Fig. 6. Initial and final ${ }^{1} \mathrm{H}$ spectra of a time-course of incubation of $H$. pylori lysates in $\mathrm{KCl}$ with $40 \mathrm{mM}$ argininosuccinate as the sole substrate at $37^{\circ} \mathrm{C}$. The resonances corresponding to the $\alpha, \beta, \gamma, \delta, l$ and $\theta$ protons of argininosuccinate and of succinate (Suc), acetate (Ace), alanine (Ala) and lactate (Lac) are indicated on the figure. The bottom spectrum was acquired at $14 \mathrm{~min}$ and the top spectrum at $1260 \mathrm{~min}$. The protein concentration of the lysates was $4.2 \mathrm{mg}$ $\mathrm{ml}^{-1}$.

6), in agreement with the results of previous investigations of fumarate catabolism in H. pylori (Mendz \& Hazell, 1993). Initial rates of degradation of argininosuccinase were measured by the decline of the $\theta-\mathrm{CH}_{2}$ resonances (Fig. 6), and they depended on the strain employed; the value obtained for strain UNSW 90023 was $3.5 \pm 0.5 \mathrm{nmol}$ $\min ^{-1}(\mathrm{mg} \text { protein })^{-1}(n=3)$. The activity of this enzyme was associated with the membrane fraction obtained from centrifugation of lysates. No significant degradation of argininosuccinate was observed in the supernatant fraction, or in $\mathrm{KCl}$ or $\mathrm{KCl} /$ phosphate buffer solutions.

\section{DISCUSSION}

The urea cycle (Fig. 7) is generally regarded as a function useful only to multicellular organisms. Urea is a relatively non-toxic compound in which excess nitrogen can be stored until it is excreted by the appropriate organs. Excretion of urea in single-cell organisms does not ordinarily pose a problem because this metabolite will be removed from the vicinity of the cells by simple diffusion. Complete urea cycle function together with urease activity has been described in only a limited number of prokaryotes, including Paracoccus denitrificans (Hiort et al., 1967) and Sporosarcina ureae (Gruninger \& Goldman, 1988), although micro-organisms of several other genera such as Agrobacterium sp. (Vissers et al., 1981 ; Dessaux et al., 1986), Bacillus sp. (Ramaley \& Bernlhor, 1965; Soru, 1983; Patchett et al., 1991), cyanobacteria (Weathers $e$ t al., 1978; Gupta \& Carr, 1981), Escherichia coli (Kharamov \& 


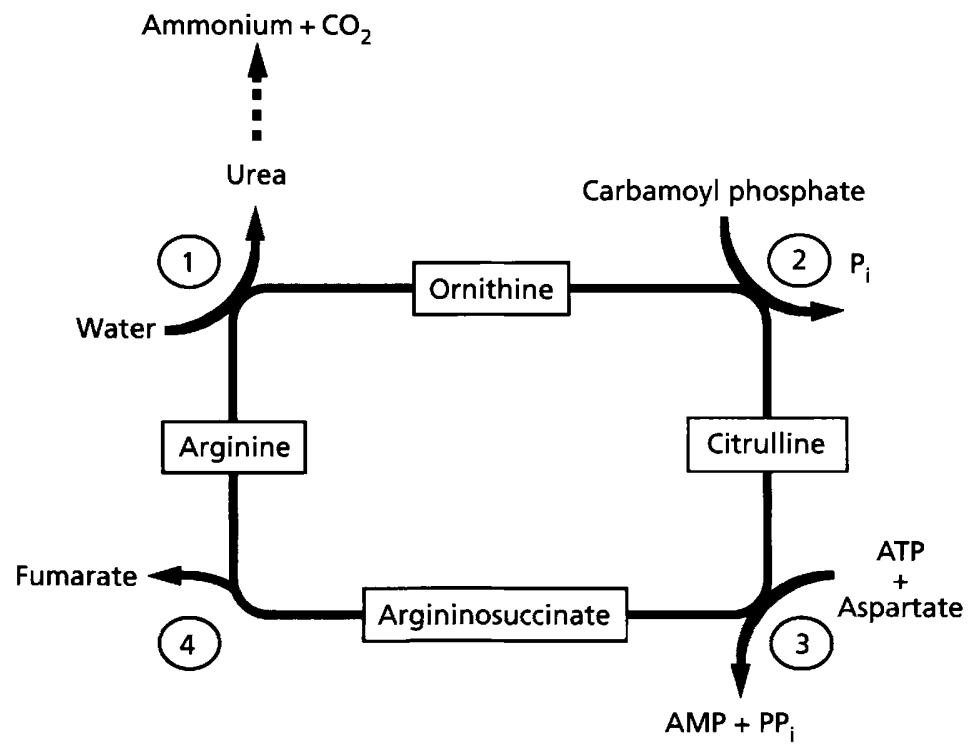

Fig. 7. Diagram of the urea cycle showing intermediate metabolites in boxes and the enzymic reactions of the cycle at the corners with arrows indicating the direction of the reactions. The enzymes are indicated by numbers: 1, arginase; 2, OTCase; 3, argininosuccinate synthetase; 4, argininosuccinase. The hydrolysis of urea by urease is indicated by a dotted line.
Kharats, 1969; Sans et al., 1988), mycobacteria (Zeller et al., 1954), Proteus sp. (Prozesky et al., 1973), Rhodobacter capsulatus (Moreno-Vivián et al., 1992), Stapbylococcus sp. (Soru \& Zaharia, 1976) and Streptomyces sp. (Vargha et al., 1983; Bascarán et al., 1989) are reported to have arginase activity, which is suggestive of a complete urea cycle. In these bacteria, the metabolism of arginine occupies a central role in the overall nitrogen metabolism of the cells.

Fast rates of arginine catabolism were measured in membrane fractions, lysates and cell suspensions by NMR spectroscopy (Fig. 1). The reaction was unidirectional with complete utilization of arginine after allowing sufficient time, and ornithine was one of the products formed (Figs 2 and 3). Ornithine is formed as a product of arginine catabolism via the arginase pathway, in which arginine is converted directly to ornithine and urea (Fig. 7 ), or via the arginine deiminase pathway, in which arginine is converted to citrulline and ammonium, and citrulline reacting with inorganic phosphate yields ornithine and carbamoyl phosphate. To distinguish between these possibilities, the utilization of arginine by the ureasenegative $\mathrm{N} 6$ ure $G:$ : $\mathrm{Km}$ strain, derived from the parent $\mathrm{N} 6$ strain by insertional mutagenesis, was investigated. Incubation of cell suspensions of the mutant strain with arginine as the sole substrate produced ornithine and urea as the main products (Fig. 4), indicating a hydrolytic cleavage of the substrate by arginase activity. Further evidence supporting the conclusion that arginine was catabolized via the arginase pathway was obtained by incubating bacterial lysates with citrulline or citrulline and ammonium as substrates. No catabolism of citrulline was observed with any of the strains.

Data obtained studying the chemical and enzymic reactions of carbamoyl phosphate with ornithine, citrulline and $N \alpha$-acetylornithine employing NMR spectroscopy and radioactive tracer analysis suggested the existence of anabolic and catabolic OTCase activities, although the results do not distinguish whether these activities cor- respond to one enzyme assayed in the forward and reverse directions or to two different enzymes. The presence of both enzymic reactions together with significant contributions from the corresponding chemical reactions precluded the determination of kinetic parameters under these conditions.

The enzyme activities involved in the synthesis and catabolism of argininosuccinate, a typical intermediate of the urea cycle, were detected and measured employing ${ }^{1} \mathrm{H}$-NMR spectroscopy (Figs 5 and 6). The existence of the urea cycle in $H$. pylori was suggested by the presence of arginase, OTCase, argininosuccinate synthetase and argininosuccinase activities (Fig. 7).

Energetically expensive futile cycles involving the enzymes of the urea cycle are avoided in eukaryotes by the presence of intracellular compartments, with the synthesis of citrulline occurring in the mitochondrial matrix and the other three reactions taking place in the cytosol. This structural compartmentalization may not be present in simpler organisms, which consequently may have developed different strategies to avoid potential futile cycles; for instance, the activity of Neurospora crassa OTCase is regulated by the level of arginine (Bates et al., 1985). Another strategy is the development of catalytic units formed by multienzyme complexes or association of enzymes with cellular components such as membranes, cytoskeleton, etc. An example is the association of arginase and OTCase in Saccharomyces cerevisiae (Eisenstein et al., 1986). The result of these strategies is the separation of biosynthetic and degradative pathways, thus achieving 'metabolic compartmentalization' without physical compartmentalization. In H. pylori, arginase and argininosuccinase activities were associated with the particulate fractions obtained by centrifugation of bacterial lysates, whereas transcarbamoylase and argininosuccinate synthetase activities were observed in the supernatant fractions, suggesting that the bacterium may achieve an energy-effective cycle by metabolic compartmentalization. 
Ornithine is accumulated in $H$. pylori cultures growing in broth (Mendz \& Hazell, 1995), indicating that the rates of production of this amino acid are higher than its rates of metabolic utilization. The irreversibility of the arginase reaction and the fast rates measured for this enzyme would explain the increase of ornithine levels with time in vitro. The OTCase activity in the catabolic direction is considerably less than in the direction of citrulline synthesis, and elevated ornithine levels would contribute to the net flux of the pathway being in the anabolic OTCase direction, with citrulline synthesis limited by the availability of carbamoyl phosphate.

Although the role of the urea cycle in prokaryotes is unclear, one of its possible functions is arginine biosynthesis, since the generation of this amino acid from ornithine utilizes three of the metabolic steps of the cycle. The high activity of $H$. pylori arginase found in this study and the essential requirement of arginine for growth of the bacterium (Reynolds \& Penn, 1994) suggested that arginine anabolism is not a major function served by the cycle. At the same time, it does not appear that arginine is a nitrogen source for the micro-organism because ammonium can be readily obtained by fast deamination of asparagine, aspartate and glutamine (Mendz \& Hazell, 1995).

Urease is highly expressed in $H$. pylori, and considerable speculation regarding its physiological and pathological roles (Hazell, 1992) followed the initial reports of its activity in the bacterium (Owen et al., 1985; Hazell et al., 1986). It has become accepted that urease functions as an environmental modulator, protecting the micro-organism from the toxic effects of gastric acidity by raising the $\mathrm{pH}$ of its microenvironment. The enzyme will hydrolyse urea to carbonic acid/bicarbonate and ammonia/ammonium, thus contributing to buffering any acidic $\mathrm{pH}$ in the proximity of the bacterium. There is evidence that urease can protect $H$. pylori from acid damage, but there is no clear-cut evidence for such a need in the niche occupied by H. pylori in the gastric mucosa of the antrum of the stomach, nor has it been established that production of a cloud of ammonia is its exclusive, or even principal, role in vivo. Recent studies with urease-negative isogenic mutants demonstrated that urease activity is essential for $H$. pylori colonization of gnotobiotic piglets, but protection from gastric $\mathrm{pH}$ does not seem to be a major role of the enzyme in promoting colonization, since the mutants failed to colonize animals maintained in an achlorhydric state (Eaton \& Krakowka, 1994).

The results of this study suggest the possibility that $H$. pylori urease may be pivotal in maintaining intracellular nitrogen balance in the micro-organism. Excess nitrogen inside the cells produced by fast catabolism of amino acids (Mendz \& Hazell, 1995) could be disposed of by excretion via the urea cycle (Fig. 7). The association of arginase with the bacterial membrane would place the enzyme in a good position to carry out this function. Hydrolysis of urea by urease outside the cells would avoid the formation of a concentration gradient that may drive this metabolic product back into the cytosol (Fig. 7). This role of urease is compatible with an acid-protection function and relates the high expression of this enzyme to the central metabolism of $H$. pylori.

\section{ACKNOWLEDGEMENTS}

This work was made possible by the support of the National Health and Medical Research Council of Australia.

\section{REFERENCES}

Bascarán, V., Mardisson, C. \& Braf̂a, A. F. (1989). Isolation and characterization of nitrogen-deregulated mutants of Streptomyces clavuligerus. $J$ Gen Microbiol 135, 2475-2482.

Bates, M., Weiss, R. L. \& Clarke, S. (1985). Ornithine transcarbamylase from Neurospora crassa: purification and properties. Arch Biochem Biophys 239, 172-183.

Calam, J. (1993). The pathogenesis of Helicobacter pylori infection and duodenal ulcer: the role of gastrin and other soluble factors. In Helicobacter pylori Biology and Clinical Practice, pp. 239-255. Edited by C. S. Goodwin \& B. W. Worsley. Boca Raton, FL: CRC Press.

Dessaux, Y., Petit, A., Tempé, J., Demarez, M., Legrain, C. \& Wiame, J. M. (1986). Arginine catabolism in Agrobacterium strains: role of the Ti plasmid. $J$ Bacteriol 166, 4450.

Eaton, K. A. \& Krakowka, S. (1994). Effect of gastric $\mathrm{pH}$ on ureasedependent colonization of gnotobiotic piglets by Helicobacter pylori. Infect Immun 62, 3604-3607.

Eaton, K. A., Dewhirst, F. E., Radin, M. J., Fox, J. G., Paster, B. J., Krakowka, S. \& Morgan, D. R. (1993). Helicobacter acinonyx sp. nov., isolated from cheetahs with gastritis. Int J Syst Bacteriol 43, 99-106.

Eisenstein, E., Duong, L. T., Ornberg, R. L., Osborne, J. C., Jr \& Hensley, P. (1986). Regulation of arginine metabolism in Saccharomyces cerevisiae. J Biol Chem 25, 12814-12819.

Ferrero, R. L., Cussac, V., Courcoux, P. \& Labigne, A. (1992). Construction of isogenic urease-negative mutants of Helicobacter pylori by allelic exchange. J Bacteriol 174, 4212-4217.

Goodwin, C. S., Armstrong, J. A. \& Marshall, B. J. (1986). Campylobacter pyloridis, gastritis, and peptic ulceration. J Clin Patbol 39, 353-365.

Gottschalk, G. (1985). Bacterial Metabolism, 2nd edn, pp. 1-4. New York: Springer-Verlag.

Graham, D. Y. (1991). Helicobacter pylori. Its epidemiology and its role in duodenal ulcer disease. J Gastroenterol Hepatol 6, 105-113.

Gruninger, S. E. \& Goldman, M. (1988). Evidence for urea cycle activity in Sporosarcina ureae. Arch Microbiol 150, 394-399.

Gupta, M. \& Carr, N. G. (1981). Enzymology of arginine metabolism in heterocyst forming cyanobacteria. FEMS Microbiol Lett 12, 179-181.

Hazell S. L. (1992). The role of Helicobacter pylori urease. A contentious issue. Eur J Gastroenterol Hepatol (Suppl 1) 4, S55-S59.

Hazell, S. L., Lee, A., Brady, L. \& Hennessy, W. (1986). Campylobacter pyloridis and gastritis: association with intercellular spaces and adaptation to an environment of mucus as important factors in colonization of the gastric epithelium. J Infect Dis 153, 658-663.

Hiort, U., Kleczkowski, K. \& Kating, H. (1967). Untersuchungen zum Stoffwechsel des Harnstoffs in Mikroorganismen. VI. Die spezifischen Aktivitäten der Enzyme des Ornithin-Cyclus in Micrococcus denitrificans Beij. Arch Mikrobiol 55, 311-319.

International Agency for Cancer Research (1994). Monographs on the Evaluation of Cancer Risks to Humans, vol. 61, pp. 177-240. Lyon: World Health Organization. 
Kharamov, V. A. \& Kharats, K. S. (1969). The arginase activity of Escherichia coli. Zt Mikrobiol Epidemiol Immunobiol 69, 120-123.

Lee, A. (1989). Campylobacter pylori and CLO in animals: overview of mucus-colonizing organisms. In Campylobacter pylori and Gastroduodenal Disease, pp. 246-260. Edited by B. J. Rathbone \& R. V. Heatley. Oxford: Blackwell Scientific.

Mendz, G. L. \& Hazell, S. L. (1993). Fumarate catabolism by Helicobacter pylori. Biochem Mol Biol Int 31, 325-332.

Mendz, G. L. \& Hazell, S. L. (1995). Amino acid utilization by Helicobacter pylori. Int J Biochem Cell Biol 27, 1085-1093.

Mendz, G. L., Hazell, S. L. \& van Gorkom, L. (1994). Pyruvate metabolism by Helicobacter pylori. Arch Microbiol 162, 187-192.

Miles, A. A. \& Misra, S. S. (1938). The estimation of the bactericidal power of blood. J Hyg 38, 732-749.

Moreno-Vivián, C., Soler, G. \& Castillo, F. (1992). Arginine catabolism in the phototrophic bacterium Rbodobacter capsulatus E1F1. Eur J Biochem 204, 531-537.

Morris, A. \& Nicholson, G. (1987). Ingestion of Campllobacter pyloridis causes gastritis and raised fasting gastric $\mathrm{pH} . A m J$ Gastroenterol 82, 192-199.

Nedenskov, P. (1994). Nutritional requirements for growth of Helicobacter pylori. Appl Environ Microbiol 60, 3450-3453.

O'Rourke, J. L., Solnick, J., Lee, A. \& Tompkins, L. S. (1992). Helicobacter heilmanii (previously Gastrospirillum), a new species of Helicobacter in humans and animals. Ir J Med Sci (Suppl 10) 161, 31.

Owen, R. J., Martin, S. R. \& Borman, P. (1985). Rapid urea hydrolysis by gastric Campylobacters. Lancet $\mathbf{i}, 111$.

Patchett, M. L., Daniel, R. M. \& Hugh, W. M. (1991). Characterisation of arginase from the extreme thermophile Bacillus caldovelox. Biochim Biopbys Acta 1077, 291-298.

Prozesky, O. W., Grabow, W. O. K., van der Merwe, S. \& Coetzee, J. N. (1973). Arginine cluster in the Proteus-Providence group. $J$ Gen Microbiol 77, 237-240.

Ramaley, R. F. \& Bernlhor, R. W. (1965). Postlogarithmic phase metabolism of sporulating microorganisms. III. Breakdown of arginine to glutamic acid. J Mol Biol 11, 842-844.
Reynolds, D. J. \& Penn, C. W. (1994). Characteristics of Helicobacter pylori growth in a defined medium and determination of its amino acid requirements. Microbiology 140, 2649-2656.

Sans, N., Schindler, U. \& Schroeder, J. (1988). Ornithine cyclodeaminase from Ti plasmid C58: DNA sequence, enzyme properties and regulation of activity by arginine. Eur J Biochem 173, 123-130.

Soru, E. (1983). Chemical and immunological properties of $B$. anthracis arginase and its metabolic involvement. Mol Cell Biochem 50, 173-183.

Soru, E. \& Zaharia, O. (1976). Chemical and immunological specificity of arginase isolated from a pathogenic $S$. aureus strain. Rev Roum Biochem 13, 49-60.

Stanley, J., Linton, D., Burnens, A. P., Dewhirst, F. E., On, S. L. W., Porter, A. \& Costas, M. (1994). Helicobacter pullorum sp. nov. - genotype and phenotype of a new species isolated from poultry and from human patients with gastroenteritis. Microbiology 140, 3441-3449.

Vanzanten, S. J. O. V. \& Sherman, P. (1994). Helicobacter pylori infection as a cause of gastritis, duodenal ulcer, gastric cancer and nonulcer dyspepsia - a systematic review. Can Med Assoc J 150, 177-185.

Vargha, G., Karsai, T. \& Szabo, G. (1983). A conditional aerial mycelium mutant of Streptomyces fradiae with deficient ornithine carbamoyltransferase activity. J Gen Microbiol 129, 539-542.

Vissers, S., Dessaux, Y., Legrain, C. \& Wiame, J. M. (1981). Feedback inhibition by arginine of ornithine carbamoyltransferase of Agrobacterium tumefaciens. Arch Int Pbysiol Biochim 98, B83-B84.

Weathers, P. S., Chee, H. L. \& Allen, M. M. (1978). Arginine catabolism in Aphonocapsa 6308. Arch Microbiol 118, 1-6.

Zeller, A., Van Orden, L. S. \& Vogtli, A. (1954). Enzymology of mycobacteria. VII. Degradation of guanidine derivatives. $J$ Biol Chem 260, 3350-3354.

Received 15 January 1996; revised 21 May 1996; accepted 27 June 1996 